WellBeing International

WBI Studies Repository

$11-1988$

\title{
Initial Test of a Farrowing Crate with Inward-Sloping Sides
}

D. Fraser

Agriculture Canada, dfraser@mail.ubc.ca

P. A. Phillips

Agriculture Canada

B. K. Thompson

Agriculture Canada

Follow this and additional works at: https://www.wellbeingintlstudiesrepository.org/houcfani

Part of the Agribusiness Commons, Animal Studies Commons, and the Operations and Supply Chain Management Commons

\section{Recommended Citation}

Fraser, D., Phillips, P. A., \& Thompson, B. K. (1988). Initial test of a farrowing crate with inward-sloping sides. Livestock Production Science, 20(3), 249-256.

This material is brought to you for free and open access by WellBeing International. It has been accepted for inclusion by an authorized administrator of the WBI Studies Repository. For more information, please contact wbisr-info@wellbeingintl.org.

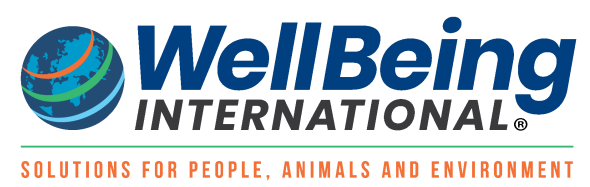




\title{
Initial Test of a Farrowing Crate with Inward- Sloping Sides
}

\author{
David Fraser, P.A. Phillips, and B.K. Thompson \\ Agriculture Canada
}

\begin{abstract}
A farrowing crate was designed with sides spaced well apart $(1150 \mathrm{~mm})$ at the sow's standing height but angled inward near the floor to restrict the sow's lying area and to prevent the sow from dropping suddenly onto one side. Survival and body-weight data were collected for 20 farrowings in the prototype crate and for 18-20 farrowings in each of 3 other crate types. No significant differences were found in stillbirth rate, other deaths to 14 days, or average piglet weight gains, but gains were somewhat more variable in one of the conventional designs which interfered with the piglets' access to the teats. The principle of inward-sloping crate sides may provide a less restrictive alternative to conventional farrowing crates, but large-scale testing is needed.
\end{abstract}

\section{INTRODUCTION}

Farrowing crates have come into wide use, mainly as a means of reducing the number of piglets crushed accidentally by the sow. Farrowing crates are generally considered to be beneficial for the piglets; however, estimates vary widely as to the actual reduction in piglet deaths attributable to their use (e.g. Robertson et al., 1966; Glastonbury, 1976; Gustafsson, 1983).

Even when crates are used, however, accidental crushing by the sow remains an important cause of death (e.g. Glastonbury, 1977; Bolet, 1982; Spicer et al., 1986; Svendsen et al., 1986). This fact has led to many modifications to crate design, some of which are highly restrictive and may make it more difficult for the sow to stand up (Baxter, 1984). Close confinement of sows is also controversial with respect to animal welfare (Baxter, 1981; Vestergaard and Hansen, 1984). In this respect, an ideal farrowing pen would provide a reasonable amount of freedom for the sow, while retaining the specialized, protected environment for the piglets.

With these considerations in mind, we have attempted to design a crate that will achieve the same management objectives as the most restrictive crates, but with less stringent confinement of the sow. The crate sides are widely spaced at the sow's standing height, but slope inward near the floor to guide the sow into a restricted central lying area. Because the new crate departs considerably from conventional designs, we conducted an initial test (limited in numbers but balanced as closely as practicable with respect to floor type, room temperature, sow parity number, and litter size) to identify any major problems. 


\section{MATERIALS AND METHODS}

\section{Design of the Ottawa crate}

Each side of the Ottawa crate (Fig. 1) consisted of 5 round vertical bars joined by horizontal pieces of flat steel. At $390 \mathrm{~mm}$ above the floor, the bars angled inward and downward at $45^{\circ}$. This low angled part of the bar was of larger diameter and ended in a curved elbow to minimize abrasion on the sow's back as was seen in an earlier prototype. The crate sides were hinged to two short posts (front and rear) that were fixed to the floor.

The crate was oriented diagonally in a pen $1.95 \times 1.95 \mathrm{~m}$ (Fig. 2). The crate sides were spaced so as to give a width of $750 \mathrm{~mm}$ from prong tip to prong tip at the sow's lying height. In the normal or "open" position (Fig. 2), the vertical sides of the crate were spaced about $1150 \mathrm{~mm}$ apart, and the sows turned around with little apparent difficulty. In the "closed" position, the sides were rotated inward so that they met above the sow. This arrangement allowed the sow to stand up and lie down with no obvious impediment. The sows did not turn around in the closed crate, although a determined, small-bodied sow could certainly have done so. In this study, the crate was kept in the closed position (to reduce the saw's movement) starting on the day when farrowing was expected, and ending when the piglets were 5 days old.

Fig. 1. End and side views of one side of the Ottawa crate.

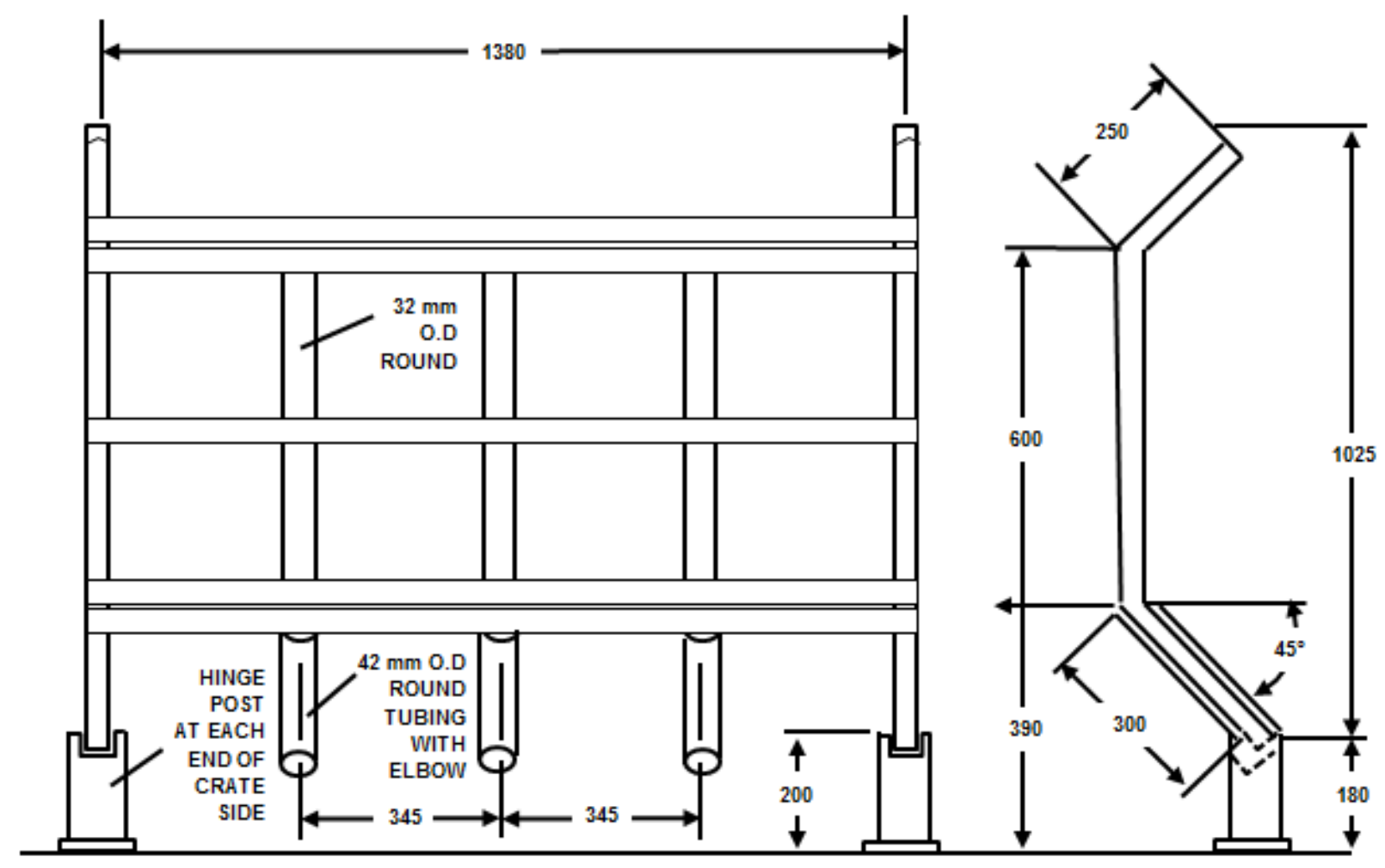

\section{Other crates tested}

Three other crates were included in the study. In the "straight-rail crate" (described by Fraser and Thompson, 1986), the sides were spaced $590 \mathrm{~mm}$ apart on centre, and each side consisted of 4 straight, horizontal bars. The "flared-rail crate" was a more modern design, narrow above and wider below. Each 
side of the crate consisted of 3 straight horizontal bars spaced $470 \mathrm{~mm}$ apart on centre, and a fourth (lowest) horizontal bar, $235 \mathrm{~mm}$ above the floor, which was flared outward from the sow to a spacing of $795 \mathrm{~mm}$ on centre. The "finger crate," based on a design by Gadd (1982), included a series of angled "fingers" or prongs. Each side of the crate consisted of 4 straight horizontal bars spaced $550 \mathrm{~mm}$ apart on centre, with 6 prongs attached to the lowest bar and angled away from the sow at $24^{\circ}$ from the vertical.

Fig. 2. Plan and section of the Ottawa crate and associated pen.
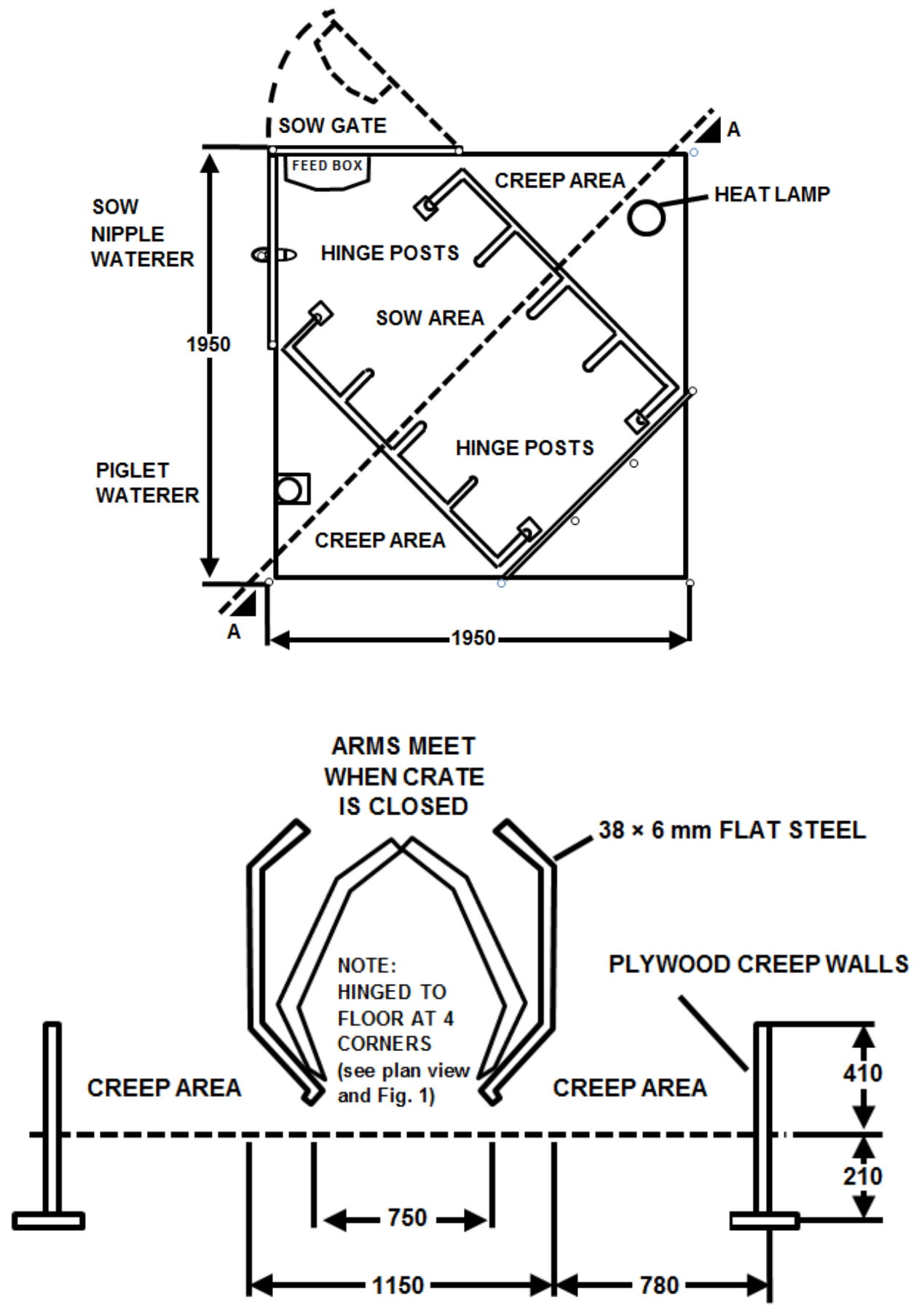

SECTION A - A 
The 3 crates were installed in rectangular pens of $3.5-3.9 \mathrm{~m}^{2}$ compared to the $3.8 \mathrm{~m}^{2}$ for the Ottawa crate. All 4 pens had plastic-coated expanded metal flooring supported by a framework of steel angle about 0.3 $\mathrm{m}$ above the concrete floor of the room. Each pen was equipped with one $250-\mathrm{W}$ heat bulb suspended $0.6 \mathrm{~m}$ above the floor, a water bowl accessible to the piglets from birth, and a piglet supplementary feeder accessible from 10 days of age.

\section{Procedures}

One crate of each of the 4 designs was installed in a temperature-controlled room (generally $20-24^{\circ} \mathrm{C}$ ). Yorkshire sows from the Animal Research Centre's specific-pathogen-free herd were housed in the crates from 5 days before farrowing until the piglets were 14 days old. Management routines are described by Thompson and Fraser (1988).

Sows were assigned to the crates as the crates became available, except that no sow was used twice in the same crate, and some effort was made to balance the parity distribution among crates. By the end, each crate had housed 6 sows of first or second parity, 7 or 8 of parity $3-4,3$ or 4 of parity $4-6$, and 3 or 4 of parity 7-10. Two sows of parity 7-10 were removed from the flared-rail crate because they seemed too cramped, so this crate had only 18 farrowings instead of 20 .

All weighing of piglets was done between $10: 00 \mathrm{~h}$ and 12:00 $\mathrm{h}$ daily, so that daily weight gains would cover a period close to $24 \mathrm{~h}$. For overnight farrowings or any farrowings that began after 16:00 $\mathrm{h}$ (the last time when sows were routinely checked each day), the first weighing at 10:00-12:00 $\mathrm{h}$ the next morning was called Day 0 . When farrowing occurred during daytime (before 16:00 h) the first weighing was considered to be on Day 1.

The data involved two phases: farrowing and rearing. Farrowing records included the number of piglets born alive and stillborn, piglet body weights at the time of first weighing, and the number of piglets that died before first weighing. Rearing performance was based on standardized litters, adjusted to 10-12 piglets by fostering at Day 1 as described by Thompson and Fraser (1988). Ten small litters were dropped from the experiment because there were no suitable piglets to add, thus leaving 16-18 litters per crate during the rearing phase. Data included piglet weights on Days 1, 2, 3, 4, 5, 7, 10 and 14, and all deaths during this period. Post-mortem examinations were carried out on all dead piglets other than stillbirths.

Weight gains during the rearing phase (Day 1-14) were compared using analysis of variance, with a model that included the 4 crate types, the 3 assigned litter sizes (10,11 or 12 piglets), and the interaction. Analysis was done on litter means and on within-litter variation in gain after log transformation. To reduce uncontrolled variation due to the piglets' 1-day weights, all weight gain values were adjusted for 1-day weight using the regression coefficient obtained from analysis of covariance, before litter means and variances were calculated.

\section{RESULTS}

Stillbirth rate was $10.0 \%$ in the Ottawa crate and $9.8-12.1 \%$ for the others. Only about $3 \%$ of live-born piglets died before the first weighing, and about $4 \%$ died between Days 1 and 14 . The differences between crates were well within sampling error (Table 1). Post-mortem examination suggested a somewhat higher incidence of physical injury in pigs that died in the Ottawa crate (10 cases) compared with the other crates (range of 4-7 cases) but the numbers were very small.

Weight gains during Days 1-14 (Table 1) showed no apparent differences among the 4 crate types $\left(F_{3,56}\right.$ $=0.45)$ nor among the 3 litter sizes $\left(F_{2,56}=1.49\right)$. Within-litter variances in weight gain (Table 1$)$ were very 
similar for the Ottawa, finger and flared-rail crates, but tended to be higher in the straight-rail crate $\left(F_{1,56}=\right.$ $3.79, P<0.06$ for the single degree of freedom contrast of the straight-rail crate vs. the others).

Table 1. Performance of piglets during the farrowing phase (birth to first weighing) and rearing phase (Days 114) for the 4 farrowing crate types.

\begin{tabular}{|c|c|c|c|c|c|c|c|}
\hline \multirow[t]{2}{*}{ Crate type } & \multicolumn{3}{|c|}{ Farrowing phase } & \multicolumn{4}{|c|}{ Rearing phase } \\
\hline & $\begin{array}{l}\text { Total }^{1} \\
\text { piglets }\end{array}$ & Stillbirths & $\begin{array}{l}\text { Deaths to } \\
\text { first } \\
\text { weighing }\end{array}$ & $\begin{array}{l}\text { Total }^{2} \\
\text { piglets }\end{array}$ & $\begin{array}{c}\text { Deaths } \\
\text { Days 1-14 }\end{array}$ & $\begin{array}{l}\text { Mean }^{3} \\
\text { liveweight } \\
\text { gain }(\mathrm{kg})\end{array}$ & $\begin{array}{c}\text { Mean }^{3} \\
\text { within-litter } \\
\text { variance in gain }\end{array}$ \\
\hline Straight rail & 229 & 27 (11.8\%) & 7 (3.1\%) & 181 & 7 (3.9\%) & 2.50 & 0.520 \\
\hline Flared rail & 190 & $23(12.1 \%)$ & $1(0.5 \%)$ & 167 & $10(6.0 \%)$ & 2.57 & 0.296 \\
\hline Finger & 244 & $24(9.8 \%)$ & 9 (3.7\%) & 196 & $3(1.5 \%)$ & 2.65 & 0.266 \\
\hline Ottawa & 230 & $23(10.0 \%)$ & $10(4.3 \%)$ & 183 & $8(4.4 \%)$ & 2.50 & 0.306 \\
\hline
\end{tabular}

${ }^{1}$ Based on 18-20 litters per crate at birth.

${ }^{2}$ Based on 16-18 litters per crate standardized to 10-12 piglets on Day 1.

${ }^{3}$ An approximate standard error is 0.11 for mean liveweight gain and 0.079 for mean within-litter variance. All gains were adjusted for initial weight by analysis of covariance before means and variances were calculated.

\section{DISCUSSION}

The only appreciable difference detected in the study was the higher within-litter variation in piglet weight gain in the straight-rail crate. A similar effect was noted in 2 previous studies (Fraser and Thompson, 1986; Thompson and Fraser, 1986) and is probably caused by the greater interference with suckling caused by the low, straight, horizontal rail. All other differences noted in this study were small. There has been some suggestion that constriction of the farrowing sow leads to prolonged farrowings (see Vestergaard and Hansen, 1984) and possibly to higher stillbirth rate, but crate design had no major effect on stillbirths in our study.

The sloping sides of the Ottawa crate limited the sow's lying area to a width of $750 \mathrm{~mm}$ (similar to that of the flared-rail crate) and appeared to be effective in slowing the descent of sows as they lay down. The openness of the crate should also allow the sow to stand up more naturally (Baxter, 1984), thus reducing sudden, uncontrolled movements of the legs which may also cause piglet injuries. The diagonal placement of the crate in the pen allowed the creep heater to be placed at the side of the sow, but still 0.6-0.7 $\mathrm{m}$ from the sow's body; this encouraged piglets to rest well away from the sow's lying area, in contrast to the situation seen with narrow side-creep areas (Baxter, 1981).

On the negative side, trampling of piglets by an active sow could be more common in the Ottawa crate because of the larger floor area on which the sow can stand. Also, the greater width of the crate made it more difficult for attendants to force a sow out of the crate if she was unwilling to leave. Because the sow can turn around in the Ottawa crate, urine and feces can be deposited at either end of the sow's area, and the manure handling system must accommodate this. However, fouling of the feeder rarely occurred.

As to economy of construction, the Ottawa crate has both advantages and disadvantages. The crate requires more steel than conventional designs, and would be somewhat more expensive to build. It fits into a pen of $3.8 \mathrm{~m}^{2}$, a size well within the normal commercial range, but still larger than the smallest pens $\left(3.3 \mathrm{~m}^{3}\right)$ in common use. However, the Ottawa crate requires only one access corridor: since sows can turn around in the crate, they can enter and leave via the same corridor and gate, without having to be backed into or out of the crate. 
In our prototype, the hinging arrangement allowed the Ottawa crate sides to be moved to a "closed" position. With the crate closed, the sows did not turn around, although they still had more freedom of movement than in other crates. The option of closing the crate might be helpful: (1) for sows that try to jump over the crate sides, although this did not happen in our study; (2) to facilitate handling the piglets or assisting in the farrowing of an aggressive sow; (3) to reduce the sow's movements and possible trampling of piglets at the time of farrowing. More study is needed to determine whether the closed position is really advantageous and at what times.

\section{ACKNOWLEDGEMENTS}

We are grateful to the staff of the Animal Research Centre pig unit, to Ms. Minka Peeters Weem and to Mr. R.A. Arcand for their cooperation in this study, and to the shop staff of the Engineering and Statistical Research Centre for constructing the prototype of the Ottawa crate. Dr. K. Hartin kindly carried out the post-mortem examinations.

\section{REFERENCES}

Baxter, S.H., 1981. Welfare and the housing of the sow and suckling pigs. In: W. Sybesma (Editor), The Welfare of Pigs. Martin us Nijhoff, The Hague, pp. 276-311.

Baxter, S., 1984. Intensive Pig Production: Environmental Management and Design. Granada, London, 588 pp., p. 455.

Bolet, G., 1982. Analyse des causes de mortalité des porcelets sous la mère. Influence du type génétique et du numéro de portée. Ann. Zootech., 31: 11-26.

Fraser, D. and Thompson, B.K., 1986. Variation in piglet weights: Relationship to suckling behavior, parity number and farrowing crate design. Can. J. Anim. Sci., 66: 31-46.

Gadd, J., 1982. European update. Natl. Hog Farmer, 27(12): 75-79.

Glastonbury, J.R.W., 1976. A survey of preweaning mortality in the pig. Aust. Vet. J., 52: 272-276.

Glastonbury, J.R.W., 1977. Preweaning mortality in the pig. The prevalence of various causes of preweaning mortality and the importance of some contributory factors. Aust. Vet. J., 53: 315-318.

Gustafsson, B., 1983. Effects of sow housing systems in practical pig production. Trans. Am. Soc. Agric. Eng., 26: 1181-1185, 1193.

Robertson, J.B., Laird, R., Hall, J.K.S., Forsyth, R.J., Thomson, J.M. and Walker-Love, J., 1966. A comparison of two farrowing systems for sows. Anim. Prod., 8: 171-178.

Spicer, E.M., Driesen, S.J., Fahy, V.A., Horton, B.J., Sims, L.D., Jones, R.T., Cutler, R.S. and Prime, R.W., 1986. Causes of preweaning mortality on a large intensive piggery. Aust. Vet. J., 63:71-75.

Svendsen, J., Bengtsson, A.C.H. and Svendsen, L.S., 1986. Occurrence and causes of traumatic injuries in neonatal pigs. Pig News Inf., 7: 159-170.

Thompson, B.K. and Fraser, D., 1986. Variation in piglet weights: Development of within-litter variation over a 5-week lactation and effect of farrowing crate design. Can. J. Anim. Sci., 66: 361-372.

Thompson, B.K. and Fraser, D., 1988. Variation in piglet weights: Weight gains in the first days after birth and their relationship with later performance. Can. J. Anim. Sci., in press. 
Vestergaard, K. and Hansen, L.L., 1984. Tethered versus loose sows: Ethological observations and measures of productivity. 1. Ethological observations during pregnancy and farrowing. Ann. Rech. Vet., 15: $245-256$. 